\title{
Optimized Analytical Techniques for Extraction and Separation of Bioactive Compounds from Diverse Plant Types \\ Suparna Mandal Biswas*
}

Agricultural and Ecological Research Unit, Indian Statistical Institute, 203, B.T. Road, Kolkata, India

\begin{abstract}
Bioactive compounds (BACs) from plants provide unlimited opportunities for pharmaceuticals and natural agrochemicals development due to vast diversity of secondary compounds. Successful identification and development of natural products from plants necessitates a standard and integrated approach to screen compounds which aids in determination of dose response activity. We examined Peperomia pellucida (herb with fibrous root), Cleome viscosa (herb with tap root), Piper chaba (climber) and Artocarpus lakoocha (tree). In C. viscosa plants, BACs were collected from 'Root Exudates Trapping System' made of Buchner funnel and conical flask, while compounds were collected from $P$. pellucida by a self-designed horizontal tube like glass ware with stopper and funnel at either end. BACs are extracted from stem and leaves dust of $P$. chaba and $A$. lakoocha respectively. The basic sequential steps are same included grinding of plant parts, homogenization, vacuum filtration followed by liquid-liquid extraction in which BACs were fractionated into two major phases (ethyl acetate layer and aqueous layer). The extracts were further purified into a single pure compound by repetitive running through column and subsequently followed by thin layer chromatography and finally subjected to spectral analyses (viz. MS, IR, ${ }^{1} \mathrm{HNMR}$ and ${ }^{13} \mathrm{CNMR}$ ) for complete molecular characterization. A new Phenol glycoside was isolated from Peperomia pellucida and Lactam nonanoic acid was recovered from Cleome viscosa. Four major compounds were recovered from Piper chaba and Artocarpus lakoocha with remarkable bioactivity but only the important fractions are described here. These new extraction techniques will extend and enhance the usefulness of plants as renewable resources of valuable chemicals.
\end{abstract}

Keywords: Bioactive compounds (BACs); Root exudates trapping system; Liquid-liquid extraction; Peperomia pellucida; Cleome viscosa; Piper chaba; Artocarpus lakoocha

\section{Introduction}

Bioactive compounds (BACs), otherwise known as the inherent silent tools of self-protection among plants or semio-chemicals in plants, have witnessed a dramatic increase in research in recent years. The use of BACs in different commercial sectors such as pharmaceuticals, food and agro-industries signify the need of the most appropriate and standard method to extract these compounds from plant materials [1]. It is true that development of modern chromatographic and spectrometric techniques make BACs analysis easier than before but the success still depends on the extraction methods [2]. The development of natural products from plants has been given a major research emphasis to discover biologically active chemicals and biochemical extracts [3]. In recent years, the plant kingdom has become an important source of major biofertilizers, herbicides, fungicides [4-6] etc. and display great diversity in chemical structure and activity. These compounds may be better than synthetic agrochemicals [7] and are much safer from health and environmental point-of-view [8] and can also be used as a renewable novel compound in eco-friendly manner. Considering this ever-growing demand of plant BACs and the variations that exist among them, it is necessary to build up a holistic approach for screening these compounds.

Cleome viscosa L. (Capparidaceae) is widely distributed sticky herb with yellow flowers, having strong penetrating odor and also possess several medicinal properties [9-14]. In our field study, we observed Cleome viscosa is the first and sole appearance species in the very adverse wasteland. Due to their lot of medicinal properties, wide distribution as well as first appearance in wasteland, made our interest to study the BACs from the root exudates of Cleome viscosa.

Peperomia pellucida, L. HBK. belongs to the family Piperaceae. It is found mainly in South American and Asian countries. It is widely distributed in the tropical and subtropical regions and is occasionally cultivated and naturalized as weed [15-17]. This plant possesses a wide range of medicinal properties [18-21] as well as wide distribution which possibly indicate the presence of bioactive compounds in the plants. Our present studies mainly focused on BACs from of Peperomia pellucida and its allelopathic effects on the surrounding rhizosphere.

Piper chaba, Hunter (Piperaceae) is a relatively less well-known spice. The stem of the plant is very much effective against cold and cough and also enhances immunity against this disease. We are therefore interested to isolate and identify the compound responsible for its medicinal properties.

Artocarpus lakoocha, Roxb. Moraceae, is a valuable tree native to India and used for fruit, furniture, timber and feed [22]. Seeds contain artocarpins (ALA I and ALA II), the isolectins which exhibit high haemagglutination activity. The tree sheds huge amount of large leaves towards the end of December till beginning of February forming a very thick layer of leaf carpet on the ground. We are therefore interested to study if there are some BACs present in the shedded leaves of Artocarpus lakoocha.

Our objectives were to establish analytical methodologies, including the extraction, isolation and characterization of BACs from different parts of diverse plant types.

*Corresponding author: Suparna Mandal Biswas, Agricultural and Ecological Research Unit, Indian Statistical Institute, 203, B.T. Road, Kolkata 700108, India Tel: (+91)(033)25753225; Fax: (+91)(033)25753049; E-mail: suparna@isical.ac.in

Received: December 01, 2016; Accepted: March 23, 2017; Published March 27, 2017

Citation: Biswas SM (2017) Optimized Analytical Techniques for Extraction and Separation of Bioactive Compounds from Diverse Plant Types. Biochem Anal Biochem 6: 313. doi: 10.4172/2161-1009.1000313

Copyright: (c) 2017 Biswas SM. This is an open-access article distributed unde the terms of the Creative Commons Attribution License, which permits unrestricted use, distribution, and reproduction in any medium, provided the original author and source are credited. 


\section{Materials and Methods}

\section{Bioactive compounds from Peperomia pellucida L. HBK}

Collection of root exudates: Root exudates (RE) were collected after putting the plants into the root exudates collecting glass apparatus specially designed for plants with fibrous root, e.g. Peperomia pellucida. A self-designed horizontal tube like glass ware with stopper and funnel at either end.

Isolation of the potent bioactive compounds: The entire collected $\mathrm{RE}$ of Peperomia pellucida were concentrated and then extracted with solvents of different polarities, firstly in hexane, then ethyl acetate, acetone and methanol respectively. Bioassay guided fractionation revealed the most potent fraction is the methanol fraction and we give emphasis on Fraction 4 or Methanol Fraction of Peperomia pellucida (henceforth referred to as MFPP). This fraction was then purified into a single pure compound by repetitive running through column chromatography and subsequently followed by thin layer chromatography.

Molecular characterization: The purified MFPP compounds were then subjected to Instrumental analysis (viz. MS, IR, ${ }^{1} \mathrm{HNMR}$ and ${ }^{13} \mathrm{CNMR}$ ) for complete structural characterization.

Dose response assay of MFPP or methanol fraction of $P$. pellucida on rice, mustard and gram: The allelopathic potentials of isolated and purified methanol fraction of P. Pellucida on the germination and seedling growth of rice, mustard and gram were determined by bioassay experiment. A stock solution of $1000 \mathrm{ppm}$ of MFPP (40 mg in $40 \mathrm{~mL}$ distilled water) was prepared from which dilute solutions of 500, 250, $125,62.5,3.25,15.62$ and $7.81 \mathrm{ppm}$ were made. In one experiment nine sets of petridish bioassay including control were performed. The experiment was replicated thrice. For the control $20 \mathrm{ml}$ of distilled water was added instead of the test solution. Seeds were surface-sterilized with $0.1 \%$ mercuric chloride solution, washed with distilled water and placed in petri dishes lined with filter paper. After 4 days shoot length and root length in the control and treated sets were measured [23].

\section{Bioactive compounds from Cleome viscosa, $L$.}

Collection of root exudates from Cleome viscosa: Root exudates (RE) were collected after growing the plants of Cleome viscosa in root exudates trapping systems made with $110 \mathrm{~mm}$ diameter Buchner funnel and conical flasks of $500 \mathrm{ml}$ capacity. Central part (sieve portion) of the funnels was removed and the funnels were filled with soil collected from the field. Initially a small piece of muslin cloth was put at the lower portion of the funnel for holding the soil in funnels. Funnels were kept on conical flasks painted black containing distilled water. Five to six germinated seeds of Cleome viscosa from which root exudates has to be obtained were sown in each funnel. After thinning, three to four plants, depending upon the growth or size of the plants, were allowed to grow till maturity. After attaining the age of 20-25 days, plant roots penetrated the soil of the Buchner funnels and emerged into the conical flasks containing distilled water. Root exudates were collected from the conical flasks regularly at an interval of 5-7 days and the conical flasks were filled immediately with fresh distilled water. RE collection procedure were continued for 3-4 months.

Isolation of the potent bioactive compound: The entire collected $\mathrm{RE}$ of Cleome viscosa were concentrated under hot air. The conc. RE of Cleome viscosa was then extracted with solvents of different polarities. Bioassay guided fractionation revealed the most potent fraction is the methanol fraction and also substantial amount of bioactive compounds have been recovered from this fraction and so we give emphasis on Fraction 4 or Methanol Fraction of Cleome viscosa (henceforth referred to as MFCV).

Molecular characterization: This purified crystalline MFCV compound was then subjected to Instrumental Analysis Viz. MS, FTIR, ${ }^{1} \mathrm{HNMR}$ and ${ }^{13} \mathrm{CNMR}$ for complete structural elucidation.

Antimicrobial assay: Antimicrobial activity had been performed by disc diffusion method [24]. Aqueous solution of this pure compound has been tested on bacteria (Escherichia coli, Pseudomonas aeruginosa and Staphylococcus aureus) and fungi (Aspergillusfumigatus, Aspergillius niger and Aspergillus tamarii).

\section{Bioactive compounds from the stem of Piper chaba}

Extractionof bioactive compound: About 500 gm of Piper chaba stem dust was soaked in methanol: water: acetone: ethyl acetate in the ration of 3:1:2:3 and then vortexed at $3000 \mathrm{rpm}$ by high speed mechanical stirrer for 2 hours and then filtered through sintered disc funnel. The brown colored extract was collected and concentrated in a rotary vacuum evaporator.

Isolation of the potent bioactive compound by liquid-liquid extraction method: The brown coloured concentrated aqueous extract was then taken in a separating funnel and portioned with equal volume of ethyl acetate (Figure 1). The mixture was shaken vigorously for $2 \mathrm{hrs}$ and kept overnight for settling the layer. In this technique allelochemicals got fractioned into two major groups viz. polar (remained in water layer) and non-polar (gone to ethyl acetate layer).

The Organic phase passed through anhydrous sodium sulphate and then shaken with activated charcoal to obtain a moisture free and colourless ethyl acetate fraction. It was then evaporated to dryness and dissolved in a small amount of ethyl acetate. White crystalline structure (Fraction-1) precipitated at the bottom. The supernatant ethyl acetate solution was concentrated and dropped in hexane. Fraction-2 was settled as white compound and the supernatant was concentrated to obtain Fraction-3. The aqueous phase was concentrated under hot air and dropped in methanol (approx $500 \mathrm{ml}$ ). White colour precipitate at the base was Fraction-5. The supernatant was further filtered and concentrated and dropped in acetone to get Fraction as precipitate.

We give emphasis on acetone fraction of Piper chaba because this fraction possesses hot pungent taste and henceforth referred to as PCAF.

Molecular characterization: This purified crystalline PCAF compound was then subjected to Instrumental Analysis Viz. MS, FTIR, ${ }^{1} \mathrm{HNMR}$ and ${ }^{13} \mathrm{CNMR}$ for complete structural elucidation.

Antimicrobial assay: Antifungal activity of PCAF of Piper chaba was tested on four fungal species viz. Aspergillus niger, Aspergillus fumigatus, Aspergillius tamarii and Penicillum chrysogenum. Antibacterial activity had been detected against Escherichia coli, Pseudomonas aeruginosa, Staphylococcus aureus and Sarcina lutea.

\section{Bioactive compounds from shedded leaves of Artocarpus lakoocha, Roxb.}

Isolation of compounds from shedded leaves: About $500 \mathrm{gm}$ of Artocarpus lakoocha leaf dust were taken in a round bottle Extraction flask and soaked in $1000 \mathrm{ml}$ of methanol. The entire mixture fis then vortexed at $3000 \mathrm{rpm}$ using high speed Mechanical Stirrer for $2 \mathrm{~h}$ and then filtered through sintered disc funnel. The brownish colored extract was collected and concentrated in a rotary vacuum evaporator. 


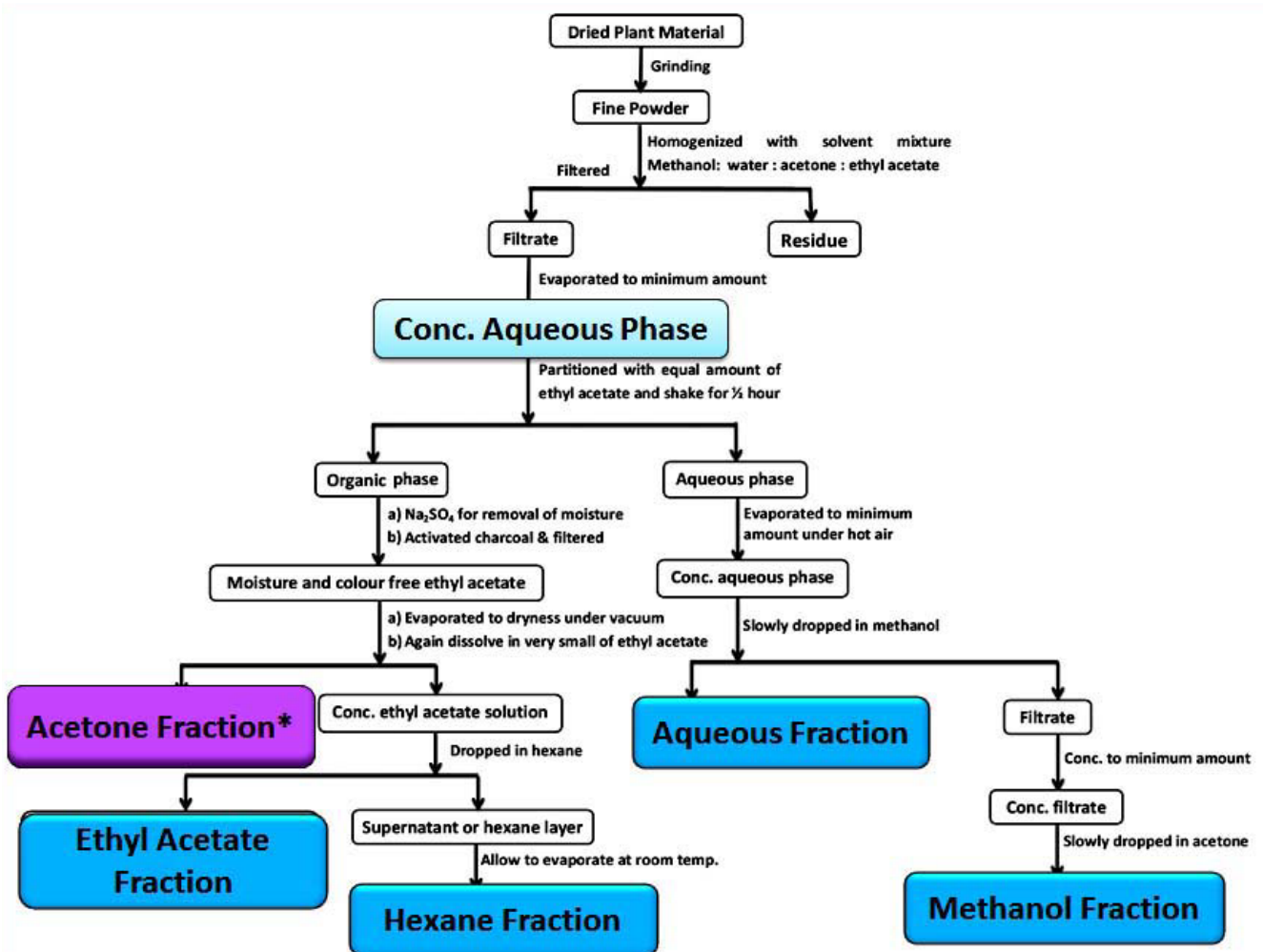

Figure 1: Schematic representation of partition, fractionation and crystallization technique of compounds from the stem of Piper chaba by Hunter.

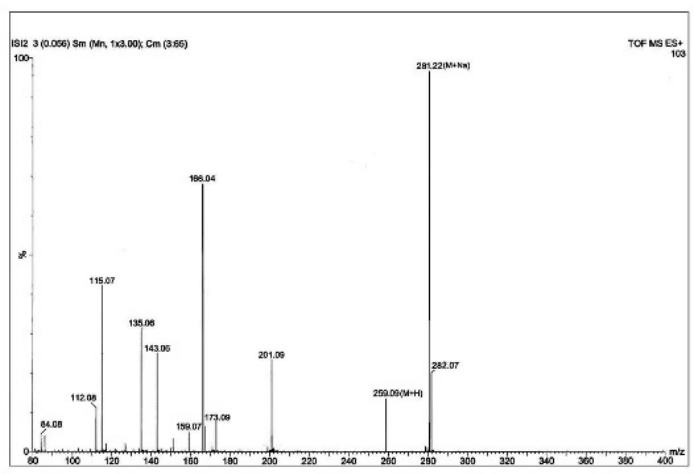

MS Spectra

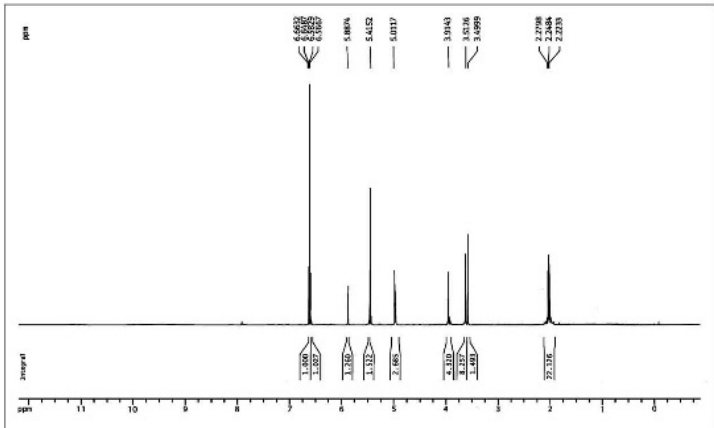

1HNMR Spectra

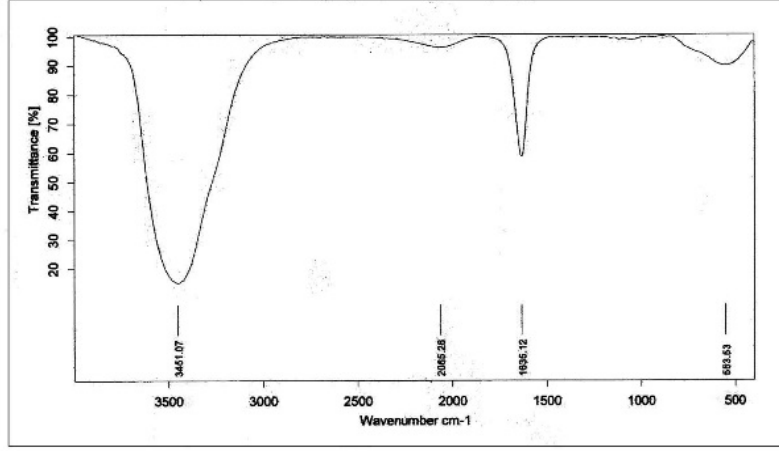

IR Spectra

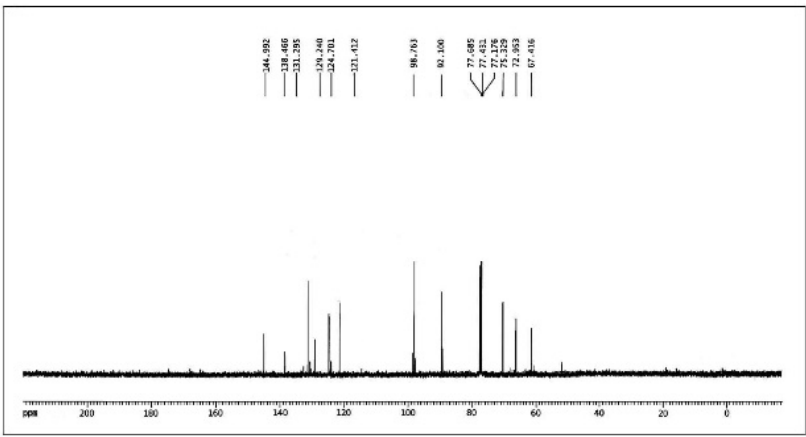

${ }^{13}$ CNMR Spectra

Figure 2: Spectral analysis of (MFPP) or methanol fraction of Peperomia pellucida (L.) HBK. 
Citation: Biswas SM (2017) Optimized Analytical Techniques for Extraction and Separation of Bioactive Compounds from Diverse Plant Types. Biochem Anal Biochem 6: 313. doi: 10.4172/2161-1009.1000313

Page 4 of 7

The conc. material of Artocarpus lakoocha was then extracted with solvents of different polarities. The compounds were then purified into a single pure compound by column chromatography and thin layer chromatography. Here we give emphasis on Hexane fraction of $A$. lakoocha or ArtclHF.

Molecular characterization: This purified ArtclHF compound was then subjected to Instrumental Analysis Viz. MS, FTIR, ${ }^{1} \mathrm{HNMR}$ and ${ }^{13} \mathrm{CNMR}$ for complete structural elucidation.

Antimicrobial assay: Agar diffusion method was performed for testing the impact of ArtclHF against three different fungal species viz. Aspergillus niger, Aspergillus tamarii and Aspergillus fumigates and on three different bacterial species such as Escherichia coli, Sercina lutea, Streptococcus aureus.

\section{Results}

\section{Bioactive compounds from the root exudates of Peperomia} pellucida, L. HBK

Molecular characterization of bioactive compounds: In

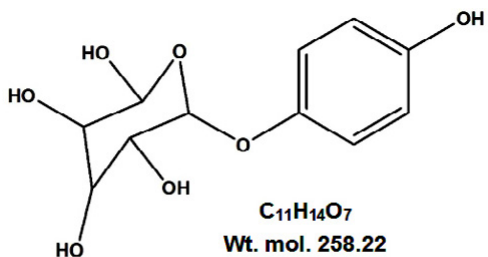

Figure 3: Molecular structure of methanol fraction of Peperomia pellucida (L.) HBK.
Peperomia pellucida, compounds recovered mainly from methanol and water fraction of which the methanol fraction contained BACs as revealed by the fractionated bioassay experiment. So, we placed emphasis on the methanol fraction of Peperomia pellucida (henceforth referred to as MFPP). Spectral analyses suggested the compound to be phenol glycoside or 6-(4-hydroxyphenoxy)-tetrahydro-2H-pyran2,3,4,5-tetraol with mol. wt. 258 (Figures 2 and 3).

Bioassay with MFPP on rice, gram and mustard: In vitro allelopathic activities of the compound were studied by rice wheat and mustard seed bioassay techniques. This compound showed maximum inhibitory activity in rice, than in wheat and mustard. In case of mustard seeds, concentration-dependent inhibitory and stimulatory activity on both shoot and root length was exhibited by this bioactive compound whereas in rice and wheat, this compound revealed almost inhibitory activity at all concentrations on both shoot and root length. At a concentration of $62.5,31.25$ and $7.81 \mathrm{ppm}$, it revealed stimulatory activity on both shoot and root length of mustard seeds.

\section{Bioactive compounds from the root exudates of Cleome} viscosa, $L$.

Molecular characterization of bioactive compounds: Spectral analyses of MFCV revealed that the compound is 2-amino-9-(4oxoazetidin-2-yl) nonanoic acid or lactam nonanoic (LNA) acid. In fact, there are no reports on the presence of lactam nonanoic acid (LNA) in Cleome viscosa (Figures 4 and 5.)

Antimicrobial assay: This lactam nonanoic acid of C. viscosa showed inhibitory activity on gram-negative, Pseudomonas aeruginosa and gram-positive, Staphylococcus aureus but had no effect on E. coli.

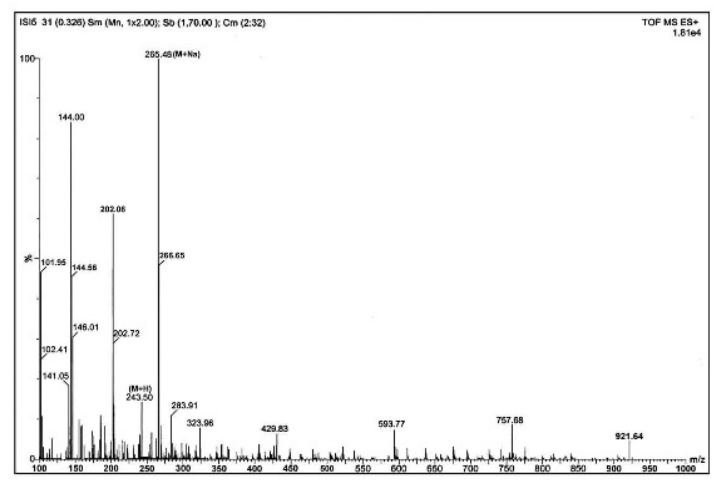

MS Spectra

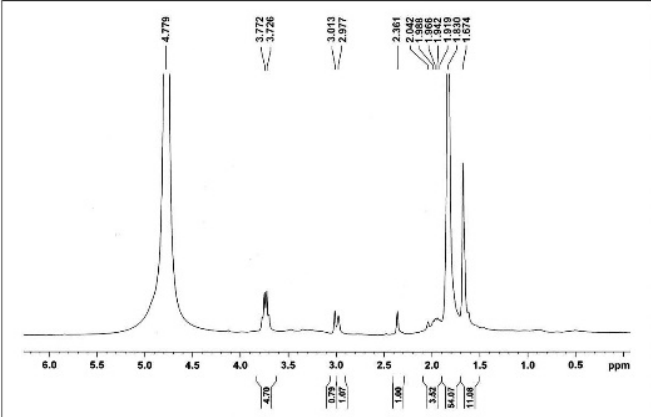

1HNMR Spectra

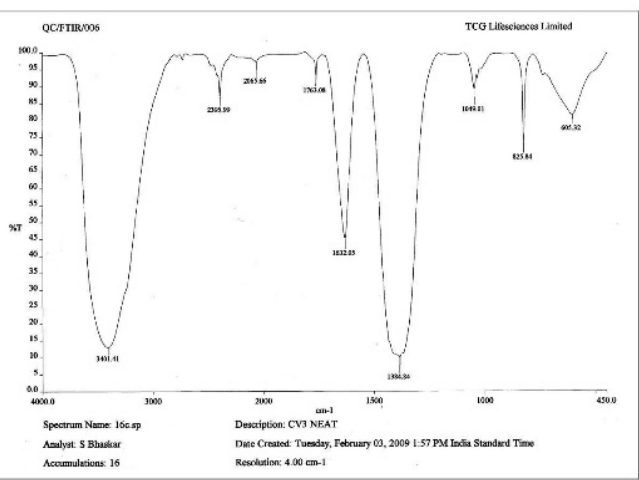

IR Spectra

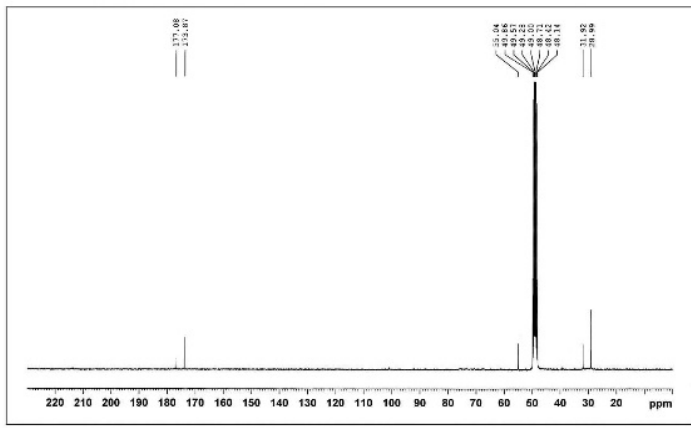

${ }^{13}$ CNMR Spectra

Figure 4: Spectral analysis of MFCV or methanol fraction of Cleome viscosa, L. 

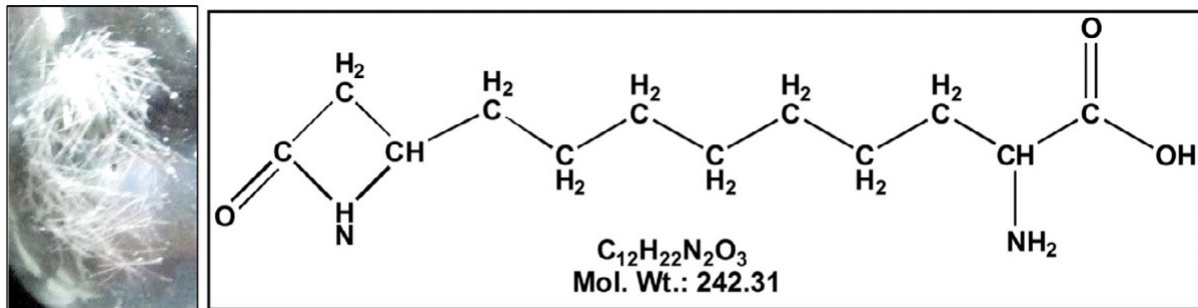

Figure 5: Molecular structure of MFCV or methanol fraction of Cleome viscosa, L.
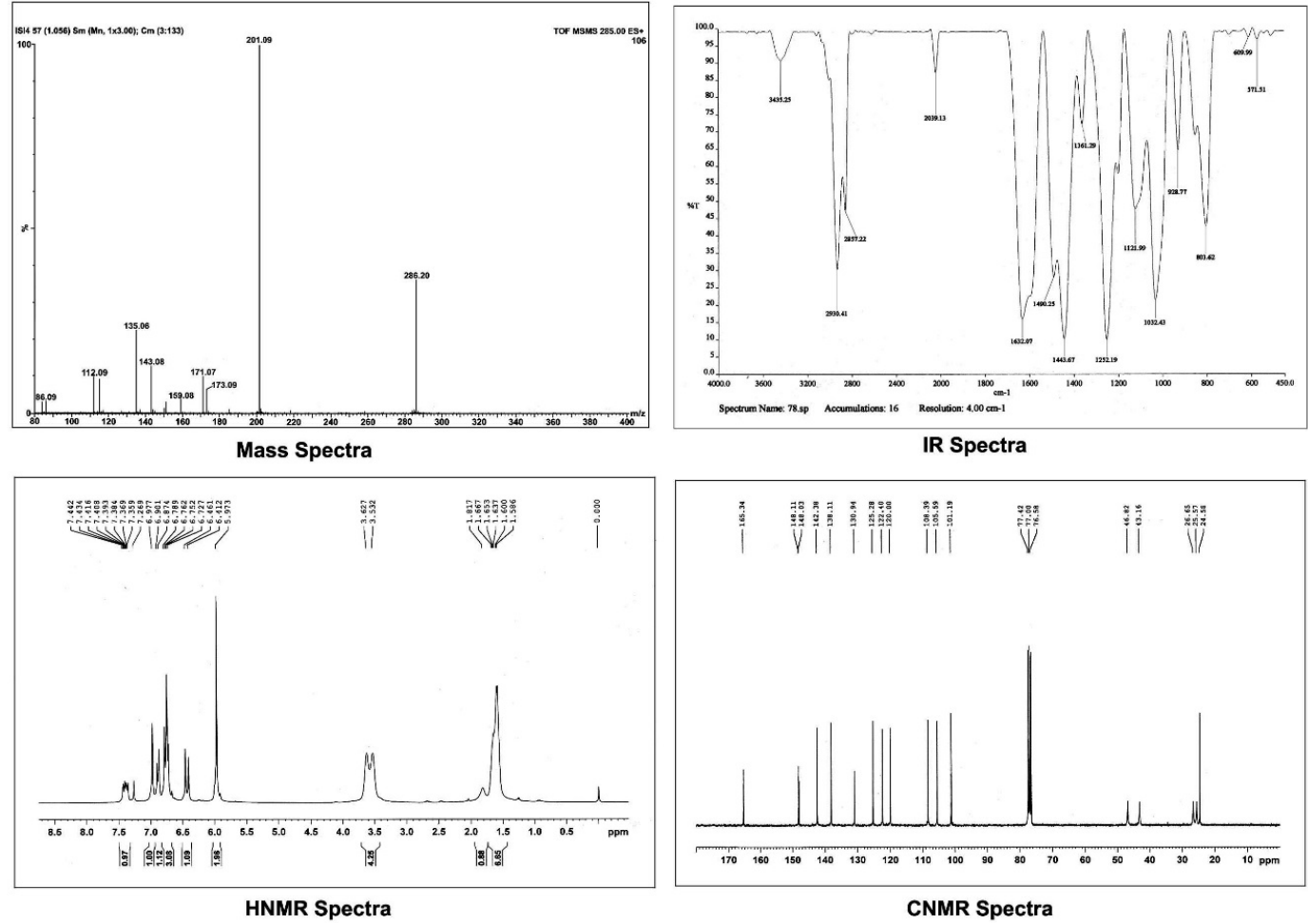

Figure 6: Spectral analysis of PCAF or acetone fraction of Piper chaba, Hunter.

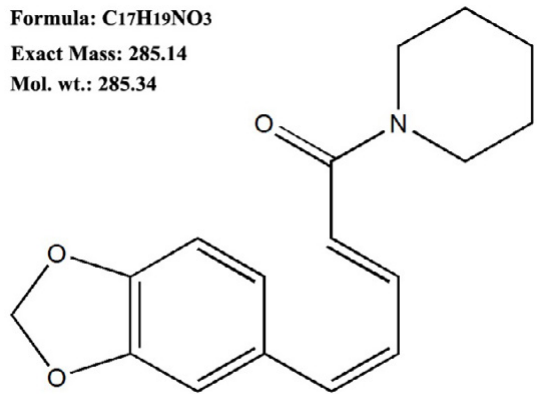

Figure 7: Molecular structure of PCAF or acetone fraction of Piper chaba, Hunter.

On the other hand, this lactam nonanoic acid stimulates the growth A. niger and A. tamarii. No effects have been detected on A. fumigates. Stimulatory effects of lactam nonanoic acid on fungi may play an important role in the ecological network.
Dose response assay of the bioactive compounds on rice, mustard and gram: The dose response assay of MFCV against rice, mustard and gram seeds showed concentration-dependent inhibitory activity. The inhibitory activity was higher in rice than in gram or mustard. In of case mustard, root length was much inhibited than shoot length by this compound.

\section{Bioactive compounds from the stem of Piper chaba, Hunter}

Molecular characterization of bioactive compounds: Spectral analyses of PCAF revealed that the compoundto be 5-Benzo- $[1,3]$ dioxol-5-y1-1-piperidin-1-yl-penta-2,4-dien-1-one or named as Chabbarin (Figures 6 and 7).

Antimicrobial assay: All four fungal species are very much sensitive to PCAF compound of Piper chaba. Aspergillius tamari is very much sensitive to chabbarin than Penicillum chrysogenum, Aspergillus niger and Aspergillus fumigatus. All the three species of Aspergillus showed maximum inhibitory activity at $2000 \mathrm{ppm}$ whereas in Penicillum chrysogenum, maximum inhibitory activity was noticed at $500 \mathrm{ppm}$. 
Citation: Biswas SM (2017) Optimized Analytical Techniques for Extraction and Separation of Bioactive Compounds from Diverse Plant Types. Biochem Anal Biochem 6: 313. doi: 10.4172/2161-1009.1000313

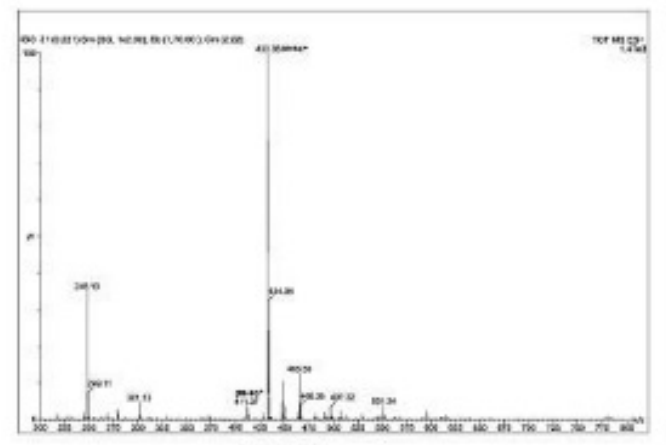

MS Spectra

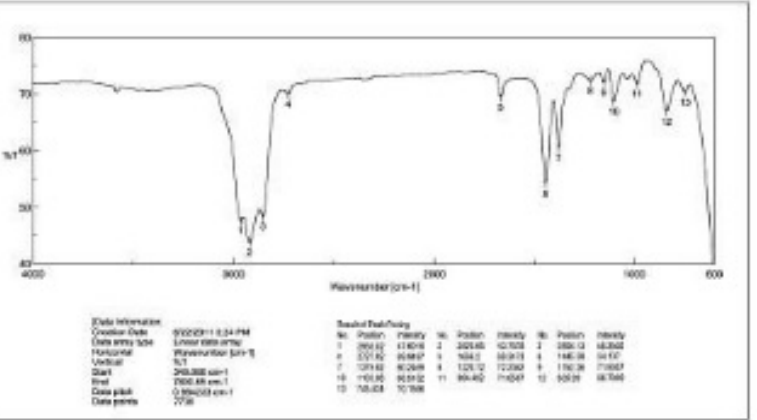

IR Spectra

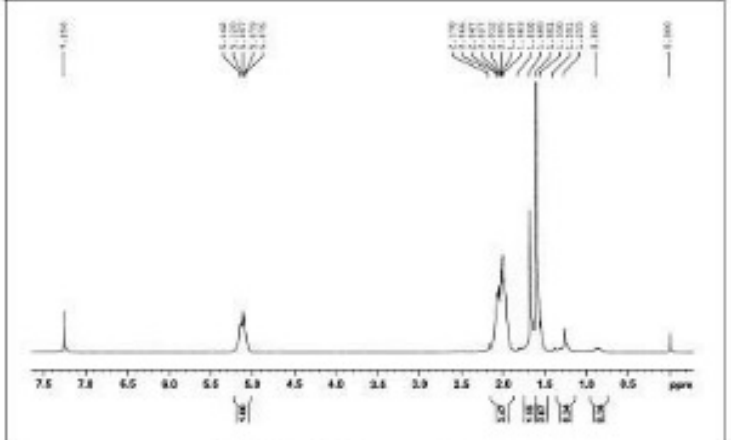

1HNMR Spectra

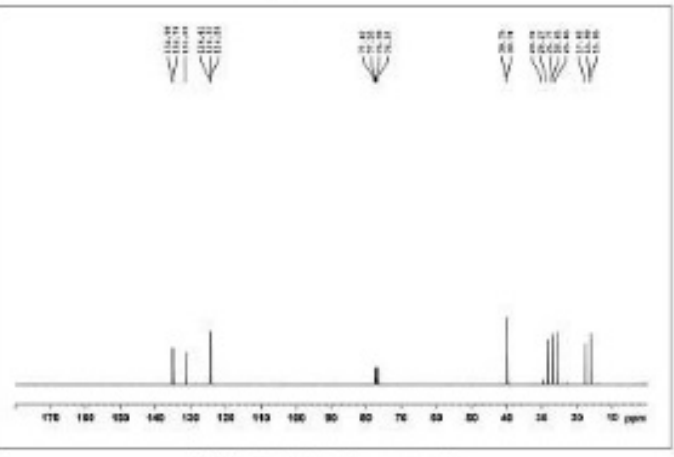

13CNMR Spectra

Figure 8: Spectral analysis of (ArtclHF) or hexane fraction of Artocarpus lakoocha, Roxb. leaves.<smiles>[B]C(C)=CC=C([B])C=CC=C(C)CCC=C(C)C</smiles>

Figure 9: Molecular structure of ArtclHF or hexane fraction of Artocarpus lakoocha, Roxb.

\section{Isolation of bioactive compounds from shedded leaves of Artocarpus lakoocha, Roxb.}

Molecular characterization of bioactive compounds: Spectral analyses of ArtclHF revealed that the compound reveals that the compound is indeed in dimeric form confirming the structure to be a known compound Squalene (Figures 8 and 9).

Antimicrobial assay: Aspergillus fumigates showed maximum inhibitory effects at 1500 and $2000 \mathrm{ppm}$. In case of Aspergillius niger maximum inhibitory effects exhibited only at $500 \mathrm{ppm}$. Aspergillius tamarii exhibited maximum inhibitory activity at $1000 \mathrm{ppm}$ and $2000 \mathrm{ppm}$.

In the inhibition zone test, Escherichia coli, Sercina lutea and Streptococcus aureus revealed differential effect at different concentrations of squalene isolated from Artocarpus lakoocha (fraction-2 compound). Escherichia coli and Sercina lutea were much inhibitorier to isolated squalene while Streptococcus aureus remained unaffected.

\section{Discussion}

Natural products from medicinal plants, either as pure compounds or as standardized extracts, provide unlimited opportunities for new drug development because of the unmatched availability of chemical diversity $[25,26]$. Due to an increasing demand for chemical diversity in screening programs, seeking therapeutic drugs from natural products, interest particularly in edible plants has grown throughout the world [27]. Botanicals and herbal preparations for medicinal usage contain various types of bioactive compounds [28,29]. The focus of this paper is on the analytical methodologies, which include the extraction, isolation and characterization of active ingredients in botanicals and herbal preparations. The qualitative and quantitative study of such bioactive compounds from plants mostly relies on the selection of proper extraction method [30,31]. Piper chaba has been traditionally used as a source of natural therapeutics [32]. In this paper we have isolated and purified four different compounds (about $20 \%$ to $22 \%$ dry weight; up to 99.9\% purity) from the stem of Piper chaba by development of unique methods of both convention and non-conventional processes with high 
Citation: Biswas SM (2017) Optimized Analytical Techniques for Extraction and Separation of Bioactive Compounds from Diverse Plant Types. Biochem Anal Biochem 6: 313. doi: 10.4172/2161-1009.1000313

efficacy. The methods assured that potential active constituents are not lost or distorted during extraction. However, the efficiency of liquidliquid extraction and chromatographic processes depends largely on the choice of solvents and the targeted plant material characteristics because the biologically active entity is often present only as a minor component in the extract. As the intended compounds may vary from non-polar to polar, for piper stem we followed the elutropic series starting from highly non polar solvent as hexane to highly polar solvent as methanol. The chromatographic processes were followed only after liquid-liquid extraction was done with crude materials. A single plant stem extract giving rise to multiple fractions is a result of optimized separation protocols.

The increased environmental pressure, toxicological concern and incidence of pesticide resistance are encouraging the need for plantderived compounds being used in agricultural fields. Plants are a virtually abundant reservoir of natural pesticides or bio fertilizers and the extraction, isolation and characterization of the active constituents from plants only can serve as a commercially successful alternate.

\section{Conclusion}

The use of bioactive compounds in different commercial sectors such as pharmaceutical, food and chemical industries signifies the need of the most appropriate and standard method to extract these active components from plant materials. The present study demonstrated the methods of isolation and purification of bioactive compounds from the crude extracts of different plant parts. The quantification and the identification of compounds in the crude extract and active bands isolated by preparative TLC were accomplished using GC-MS analysis. These methods would be used in exploring chemical properties of bioactive compounds from medicinal plants.

\section{Acknowledgement}

I am privileged to convey my sincere gratitude to our respected Director, Prof. Sanghamitra Bandhopadhyay, Indian Statistical Institute, for providing Laboratory facilities and financial support. I am indebted to Prof. Pabitra Banik, Prof-in-Charge, Biological Sciences Division; Dr. Sabyasachi Bhattacharya, Head, Agricultural and Ecological Research Unit, Indian Statistical Institute, for their affectionate encouragement, valuable advice and enormous laboratory facilities.

\section{References}

1. Pool SK, Dean TA, Oudsema JW, Poole CF (1990) Sample preparation for chromatographic separation: An overview. Analytica Chimica Acta 236: 3-42.

2. Cannell RJP (1998) Natural Products Isolation. Human Press Inc. New Jersey 165-208.

3. Cos P, Vlietinck AJ, Berghe DV, Maes L (2006) Anti-infective potential of natural products: how to develop a stronger in vitro 'proof-of-concept'. J Ethnopharmacol 106: 290-302.

4. Bhowmik PC, Inderjit S (2003) Challenges and opportunities in implementing allelopathy for natural weed management. Crop Protection 22: 661-671.

5. Dayan FE, Cantrell CL, Duke SO (2009) Natural products in crop protection Bioorg Med Chem 17: 4022-4034

6. Dayan FE, Duke SO (2010) Natural products for weed management in organic farming in the USA. Outlooks Pest Manag 21: 156-160.

7. Dossey AT (2010) Insects and their chemical weaponry: new potential for drug discovery. Nat Prod Rep. 27: 1737-1757.

8. Inderjit S, Mukerji KG (2006) Allelochemicals: Biological control of plant pathogens and diseases (Disease Management of Fruits and Vegetables), Delhi, India.

9. Devi BP, Boominathan R, Mandal SC (2002) Evaluation of anti-diarrheal activity of Cleome viscosa L. extract in rats. Phytomedicine 9: 739 - 742.

10. Devi BP, Boominathan R, Mandal SC (2003) Evaluation of antipyretic potential of Cleome viscosa Linn. (Capparidaceae) extract in rats; Journal of Ethnopharmacol 87: 11-13

11. Rastogi B, Jain S, Tiwari U, Gupta S, Saraf DK (2003) Evaluation of hepatoprotective activity of Cleome viscosa and the synergistic effects of some antihepatotoxic plant extracts in rats. J Current Sci 3: 403-408.

12. Wongkham $S$, Wongkham $C$, Boonsiri $P$, Simasathiansophon $S$, Trisonthi $C$ et al. (1995) Isolectins from seeds of Artocarpus lakoocha. Phytochemistry 40 $1331-1334$

13. Gupta N, Dixit VK (2009) Evaluation of hepatoprotective activity of Cleome viscosa Linn. Extract. Indian J. Pharmacol. 41: 36-40.

14. Joshee N, Bastola DR, Agrawal VP, Yadav AK (2002) Lakoocha: A multipurpose tree of warm climate. Perspectives on new crops and new uses. 405-406.

15. Arrigoni-Blank Mde F, Oliveira RL, Mendes SS (2002) Seed germination, phenology, and anti-edematogenic activity of Peperomia pellucida (L.) H.B.K. BMC Pharmacol 2: 12-19.

16. Ghani A (1998) Medicinal plants of Bangladesh. Bangladesh, Asiatic Society of Bangladesh 77-78.

17. Mosango DM (2008) Peperomia pellucida (L.) Kunth. In Prota 11(1): Medicina Plants/Plantesmédicinales 1; Schmelzer, G.H., Gurib-Fakim, A (Edn) PROTA Wageningen, The Netherlands.

18. Ragasa CY, Dumato M, Rideout JA (1998) Antifungal compounds from Peperomia pellucida. Chem Res Commun (ACGC) 7: 54-61.

19. Bojo AC, Albano-Garcia E, Pocsidio GN (1994) The anti-bacterial activity of Peperomia pellucida (L.) HBK (Piperaceae). Asia Life Sci 3: 35-44.

20. Smith RM (2003) Before the injection - Modern methods of sample preparation for separation techniques. J Chromatogr A 1000: 3-27.

21. Antoniolli A, Arrigoni-Blank M, Dmitrieva E, Franzotti E, Andrade M, et al. (2003) Anti-inflammatory and analgesic activity of Peperomia pellucida (L.) HBK (Piperaceae). Journal of Ethnopharmacology. 91: 215-218

22. Panday KK, Nösberger J (1985) Nutrient contents of the leaves of the fodder tree Artocarpus lakoocha Roxb. Agroforestry Systems 3: 297-303.

23. Mandal S (2001) Allelpathic activity of root exudates from Leonurus sibiricus L. (Raktodrone). Weed Biology and Management 1: 170-175.

24. Biswas SM, Bhattacharya S, Chanda S, Kumar L (2009) 3, 4-dihydroxy benzy ester derivative, a potent biopesticide isolated from leaves of Tectona grandis L. Biopesticides International 5: 24-34.

25. Cutler S, Cutler HG (2000) Biologically active natural products: pharmaceuticals. CRC Press.

26. Samuelson G (1999) Drugs of natural origin: A Textbook of Pharmacognosy. Taylor \& Francis Ltd.

27. Palombo EA (2011) Traditional medicinal plant extracts and natural products with activity against oral bacteria: Potential application in the prevention and treatment of oral diseases. Evidence-Based Complementary and Alternative Medicine 1-15.

28. Ingale AG, Hivrale AU (2010) Pharmacological studies of Passiflora sp. and their bioactive compounds. African Journal of Plant Science. 4: 417-426.

29. Cowan MM (1999) Plant products as antimicrobial agents. Clinical Microbiology Reviews 12: 564-582.

30. Tiwari U, Rastogi B, Thakur S, Jain S, Saraf DK (2004) Studies on the immunomodulatory effects of Cleome viscosa. Indian Journal of Pharmaceutical Sciences 66: 171-176.

31. Silverstein RM, Webster FX (1997) Spectrometric identification of organic compound (6th edn) John Wiley \& Sons, New York.

32. Bhandari SPS, Babu UV, Garg HS (1998) A lignan from Piper chaba stems. Phytochemistry 47: 1435-1436. 